\title{
Drivers of Secondary School Students' Intention to Enrol in Science Studies
}

\author{
Tunku Badariah Tunku Ahmad ${ }^{1, *}$, Mohamad Sahari Nordin"1, Mohd Burhan Ibrahim ${ }^{1}$, \\ Enas Said Abulibdeh ${ }^{2}$ \\ ${ }^{1}$ Kulliyyah of Education, International Islamic University Malaysia, Malaysia \\ ${ }^{2} \mathrm{Al}$ Ain University of Science and Technology, United Arab Emirates
}

Received June 28, 2019; Revised September 5, 2019; Accepted September 12, 2019

Copyright $\bigcirc 2019$ by authors, all rights reserved. Authors agree that this article remains permanently open access under the terms of the Creative Commons Attribution License 4.0 International License

\begin{abstract}
This paper reports on a survey conducted in selected secondary schools in Malaysia to explore students' intention to enroll in science studies and establish whether intention would be influenced by attitude towards science, science-efficacy, subjective norm, and perceived difficulty of science subjects. Another aim of the survey was to determine if gender, ethnicity, and school location moderated the associations between intention and its predictors. The data were collected randomly from 398 15-year-old students from 38 secondary schools in Malaysia using a 15-item questionnaire. To address the research objectives, the data were analyzed with confirmatory factor analysis and structural equation modeling. The results supported the hypotheses that the four predictors were adequate to explain intention to pursue science studies, particularly attitude and science-efficacy which were the most influential predictors. Additionally, gender, ethnicity, and school location did not moderate the predictor-intention relationships. The results suggest that the planning, implementation and evaluation of efforts to enhance science participation among students should consider how to develop more science-efficacy and positive attitudes towards the subjects.
\end{abstract}

Keywords Attitude towards Science, Behavioral Intention, Science Self-Efficacy, Subjective Norm, Theory of Planned Behavior

\section{Introduction}

Science is an important school subject for the obvious reason that it gives us fundamental knowledge about how the universe and all things in it work. It bridges the gaps in our understanding of why and how things happen. Science creates new technologies and applications to make the human existence a better existence. Societies and nations will not be able to progress without the study of science. Thus, science education is a basic component of the general education that all students should be receiving in school. As our world is becoming more advanced technologically and scientifically, students will need to be scientifically literate to function and succeed in today's society. So given its huge importance, why are many students not interested in science or do not like it in school?

Global reports show that students' interest in science tends to decline with school years $[1,2]$. Researchers looking into this issue have tried to unearth the causes, linking the decline to poor instruction, personal choice, perceived difficulty [3], and limited employment opportunities $[4,5]$. Recently it has been discovered that there is a strong positive association between science interest and peer influence [6], that is, the more students perceive that their peers are interested in science, the more likely they will express an interest in it. Creating peer communities, as it turned out, affected students' interest in the subject, and hence, their intention to pursue science studies and science-related careers.

Some theories posit that actual behaviour can actually be predicted by looking at intention; in other words, intention precedes behaviour, thus it is a good predictor of behaviour. Hence, in order to know whether secondary students would pursue further studies in science (i.e., the intended actual behaviour), we put forth the following questions: "What factors influence students' intention to enroll in or pursue science studies?" According to the Theory of Planned Behaviour, three factors are at play, namely attitude, subjective norm, and perceived behavioral control. Most studies, however, focus on the students' interest and attitudes to explain students' participation in science. Although we have extensive literature discussing the roles of these factors, there is a problem of definition in the 
existing works. Terms and constructs were used interchangeably, often overlapping in meaning, and were not clearly distinguished from one another.

For instance, are "interest" and "attitude" equivalent to "participation in science"? Does participating in science mean that students are interested in the subject and have a positive attitude towards it? In their review, Potvin and Hasni [1] found that more than one-half of the 63 reports on student's interest in science published since 2000 did not explicitly define the construct; nor did 71 of the 121 articles on student attitudes towards science. Participation, interest, and attitude are three interrelated but distinct constructs, yet several studies appeared to use them rather interchangeably. Even more intriguing is the finding that an expressed interest in science does not necessarily translate into actual enrolment in the field. Meanwhile, other researchers claimed that attitude is a multidimensional construct [7] with interest forming one of its sub-dimensions. The fuzzy state of affairs surrounding the definitions of these constructs implicates the variability of the data on and analysis of students' interest and attitudes towards science, hence the conclusions and recommendations drawn from the results.

One determining feature of interest is content specificity [8], meaning that interest is not all overarching, but rather, it stems from very specific science topics, lessons, classes, subjects, courses or programs that students have experienced. Therefore, to understand student's interest in science, the data should be drawn from those who have enrolled in specific science courses like biology, physics, chemistry or other science-related school subjects. The literature suggests that this distinctive criterion about the meaning of interest has not been given due recognition in some studies on student interest in science subjects.

The focus on the two affective variables - interest and attitudes - is necessary but insufficient to explain the reasons why students decided to enrol or not in science subjects. These are the affective variables that manifest feelings and preferences $[9,10]$. Obviously there are other psychosocial variables that drive the choices of sciences subjects. For instance, students may communicate a favourable view about the sciences, but may not act or behave consistently with this view. While they may believe that science subjects promise better career opportunities, parental choices or peer influence, also known as subjective norm, may steer them away from the sciences [11]. Some may be held back by a conviction that they are not capable of overcoming the difficulties of doing science [12]. This means that having an interest in science or a positive attitude towards it does not equate having the intention to enrol in science-related subjects. In essence, students' intention is a function of a set of predictors that include social pressure, motivation and behavioural variables, which may inconsistently interact with and affect the intention outcomes. Thus far, we are not certain about the collective and individual effects of these variables.

\section{Objectives}

Using the Theory of Planned Behaviour (TPB) and Bandura's self-efficacy theory, the present study examined whether attitude, subjective norm, perceived difficulty, and self-efficacy would collectively and individually influence secondary students' intention to take up science subjects. The second objective was to explore the moderating effects of gender, ethnicity, and school location on the associations between intention and its predictors. In other words, the study aimed to test whether gender, ethnicity, and school location would interact with the manipulative predictors, resulting in variation in students' intention to enroll in the science stream.

To address the research objectives, the study employed the TPB [13], which posits that behaviour is substantially regulated by intention, defined as the subjective probability that a person will engage in a given behaviour [14] Intention represents one's motivation, readiness, and willingness to undertake a specific action or behaviour. Strong behavioural intention is reliably and systematically associated with the behaviour; it serves as an immediate antecedent of behaviour. The present study adopted the notion that behavioural intention is a close proxy of actual behaviour. The students surveyed in the study were asked the extent to which they intended to enroll in science stream by taking Physics, Chemistry or Biology.

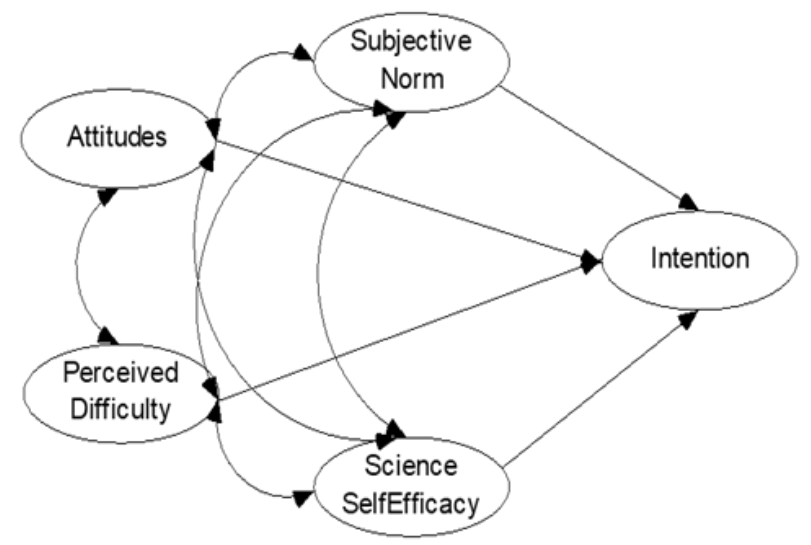

Figure 1. Hypothesized Model of Student Intention to Enrol in Science

According to the TPB, three determinants shape intention. They are attitude towards the behaviour of interest, subjective norm, and perceived behavioural control (Fig. 1). Attitude refers to the positive or negative feelings that one has about the behaviour of interest. For example, students' endorsement of the statements, "science stream offers better career opportunities" and "science subjects will help me to pursue my interest" are indicative of their positive attitude. Such an attitude will enhance any intention they may have to take up science. Subjective norm denotes social pressure; it is one's conviction about how significant others would like him to behave. In this research context, students' perception of how and whether 
they were influenced by parents, teachers and peers to take up science defines subjective norm. Finally, TPB posits that perceived behavioral control affects intention. Perceived behavioral control is defined as one's assessment of one's ability to perform a given behavior. It is about to the difficulty level of the performance in question [15]. Tasks perceived to be easy will trigger higher levels of intention. Based on the assumptions and arguments of the TPB, the study made the following hypotheses:

$\mathrm{H}_{1}$ : Attitude towards science positively affects students' intention to pursue science subjects

$\mathrm{H}_{2}$ : Subjective norm positively influences students' intention to pursue science subjects

$\mathrm{H}_{3}$ : Perceived difficulty of science influences students' intention to pursue science subjects

To further explain students' intention to enrol in science subjects, the present study examined the role of self-efficacy, which refers to a person's belief in his or her ability to accomplish set goals. Bandura [16] argues that sense of efficacy is one's causal judgment of one's ability to perform a behaviour of interest. An efficacious student is one who is committed to accomplishing challenging tasks in learning science simply because he or she finds it intrinsically rewarding [7]. Such a student has higher levels of comfort and confidence in getting good grades and in being able to master the content although it may not be easy. Thus, it is reasonable to hypothesize that:

H4: Self-efficacy in science influences students' intention to pursue science subjects

\section{Method}

Data were collected from 15-year old, lower secondary school students in Malaysia. In total, the student body comprised about 430,000 pupils, nested within 2,424 public schools. All these public schools are using centrally developed standardized curriculum. The science curriculum for the lower secondary education (grades 7-9) aims to develop students' literacy in science and technology for everyday life, and prepares them for the study of chemistry, physics and biology in higher grades.

To obtain a representative sample, the study used cluster sampling where each school served as a cluster in the targeted population. Thirty-eight (38) schools were randomly selected, and from each school, 12 pupils were systematically identified from the enrolment list. The procedure resulted in a sample of 456 students, but out of this total, only 398 copies of the questionnaire were returned and useable. This sample size was sufficient to address the research objectives, which involved testing a correlational causal model. The sample had a fair gender composition with girls making up 57\%. A majority (53\%) of the sample were Malay, while the rest were of Chinese and Indian descent. In terms of location, $43.2 \%$ of the sample attended schools in urban areas.

The study used a 15-item questionnaire containing statements related to the hypothesized four-antecedent intention model (Figure 1). The statements were the manifested indicators of the three unobserved predictors of intention, namely attitude, perceived difficulty, and subjective norm, in addition to science self-efficacy and the endogenous variable, which is intention to enroll in science subjects. Based on the results of an exploratory pilot study, three 5-point Likert scale items were used to represent each construct. High scores on each latent variable imply positive student endorsement of three of the constructs, i.e., attitude, social influence, science self-efficacy, and intention. In contrast, high scores on perceived difficulty indicate that the respondents considered science subjects easy. Thus, the construct was expected to be positively associated with intention.

\section{Results}

The data were analysed using a two-phase modelling. First, we tested the four-predictor measurement model via confirmatory factor analysis (CFA). Second, the hypothesized structural model and the alternative models were tested simultaneously to determine the overall fit, statistical significance and practical importance of the path coefficients, and the explanatory power of each model. To evaluate the research hypotheses, the study applied structural equation modelling (SEM) using the AMOS (version 20) model-fitting program. The study adopted the competing modelling strategy [17] in which we specified and tested four theoretically plausible alternative models.

\subsection{Adequacy of the Intention Measurement Model}

We evaluated the adequacy of the five measurement models (i.e., intention, attitude, subjective norm, perceived difficulty and science efficacy) using CFA and the interrelationships among these five constructs. All five measurement models showed good fit; $\chi 2 / \mathrm{df}=1.90$; CFI $=.97$; RMSEA $=.048, \mathrm{CI}: .035, .060$, suggesting that the five-factor measurement model was consistent with the data. Table 1 shows the results of the CFA, in terms of standardized factor loadings, average variance extracted (AVE), and composite reliability (CR). 
Table 1. FACTOR LOADING, AVERAGE VARIANCE EXTRACTED, AND COMPOSITE RELIABILITY

\begin{tabular}{|c|c|c|c|c|}
\hline Construct & Items & Loading* & AVE & $\mathrm{CR}$ \\
\hline \multirow{3}{*}{ Attitudes toward Science } & Science stream offers better career opportunities & .71 & \multirow{3}{*}{.51} & \multirow{3}{*}{.75} \\
\hline & Knowledge in science will benefit me in my future career & .82 & & \\
\hline & Taking science subjects will help me to pursue my interest & .59 & & \\
\hline \multirow{3}{*}{ Perceived Difficulty } & Chemistry & .91 & \multirow{3}{*}{.74} & \multirow{3}{*}{.89} \\
\hline & Physics & .80 & & \\
\hline & Biology & .86 & & \\
\hline \multirow{2}{*}{ Subjective Norm } & Father's Influence & .77 & \multirow{2}{*}{.73} & \multirow{2}{*}{.84} \\
\hline & Mother's Influence & .93 & & \\
\hline \multirow{3}{*}{ Self-Efficacy in Science } & I am confident that I can understand science subjects & .77 & \multirow{3}{*}{.57} & \multirow{3}{*}{.79} \\
\hline & I believe that I'll get good results in science subjects & .80 & & \\
\hline & $\begin{array}{l}\text { Although it is difficult, I think I will be able to master science } \\
\text { subjects }\end{array}$ & .68 & & \\
\hline \multirow{3}{*}{ Intention to Enroll } & Chemistry & .86 & \multirow{3}{*}{.70} & \multirow{3}{*}{.87} \\
\hline & Physics & .85 & & \\
\hline & Biology & .79 & & \\
\hline
\end{tabular}

*All loadings are statistically significant

\subsection{Validity of the Intention Structural Model}

Table 2 shows that all models seemed to fit reasonably well, and Model A served as the least restricted model. While the $\chi 2 / \mathrm{df}$ values were lower than the cutscore value of 5 and the RMSEAs were smaller than .06, the incremental fit indices (CFI) for the models exceeded .95 .

Table 2. PATH COEFFICIENT AND FIT STATISITIC OF COMPETING MODELS OF STUDENT INTENTION

\begin{tabular}{|c|c|c|c|c|}
\hline Indicator/ Model & A & B & $\mathrm{C}$ & $\mathrm{D}$ \\
\hline \multicolumn{5}{|l|}{ Path Coefficients $(\beta)$} \\
\hline Attitude $\rightarrow$ Intention & 0.36 & 0.56 & 0.57 & 0.7 \\
\hline Difficulty $\rightarrow$ Intention & 0.25 & 0.44 & 0.45 & \\
\hline Subjective Norm $\rightarrow$ Intention & 0.05 & 0.03 & & \\
\hline Self-Efficacy $\rightarrow$ Intention & 0.31 & & & \\
\hline \multicolumn{5}{|l|}{ Fit Information } \\
\hline$\chi^{2}$ & 172 & 140 & 140 & 160 \\
\hline df & 67 & 68 & 69 & 70 \\
\hline$\chi 2 / \mathrm{df}$ & 1.9 & 2.06 & 2.03 & 2.29 \\
\hline CFI & 0.973 & 0.967 & 0.968 & 0.959 \\
\hline RMSEA & 0.048 & 0.052 & 0.051 & 0.057 \\
\hline
\end{tabular}

Note: Antecedents of Model A: Attitude towards science; perceived difficulty; subjective norm; self-efficacy in science. Antecedents of Model B: Attitude towards science; perceived difficulty; subjective norm. Antecedents of Model C: Attitude towards science; perceived difficulty. Antecedent of Model D: Self-efficacy in science.

Since the alternative models were within nested structures, the study used the chi-square difference test to determine the optimal structure. Assuming that the least restricted model was correct, the study found that Model A outperformed Models B, C, and D. Compared to Model B, the chi-square difference test yielded statistically significant results $(\Delta \chi 2=12.67, \mathrm{p}<.001)$ in favour of
Model A. Similarly, Model A was superior to Model C and model D; $\Delta \chi^{2}=12.86, \Delta \chi^{2}=32.84$, respectively. Thus Model A, which represented the study's conceptual framework, is favoured over the other three models. In summary, the SEM produced results which were in line with the expectation that student's intention to enrol in science studies is determined by attitude, perceived difficulty, subjective norm, and science-efficacy.

\subsection{Invariance of the Intention Model}

Another objective of the study was to explore the structural invariance of students' intention to enroll in science across three likely moderators, namely gender, ethnic group, and school location. To test for gender-invariance, a simultaneous analysis on both the male $(\mathrm{n} 1=165)$ and female $(\mathrm{n} 2=255)$ samples was conducted, first allowing the structural paths to be freely estimated (meaning the results would derive an unrestricted Chi-square value), and then by constraining the structural paths (attitudes $\rightarrow$ intention; perceived difficulty $\rightarrow$ intention; $\quad$ subjective $\quad$ norm $\rightarrow$ intention; self-efficacy $\rightarrow$ intention) to be equal for the male and female groups. The analysis of this constrained intention model produced another Chi-square value, which was then tested against the baseline value for statistically significant differences. A similar procedure was used to examine the ethnic and location invariance of the intention model.

The invariance test across the male and female groups resulted in a statistically insignificant change in the Chi-square value; $\Delta \chi^{2}(\mathrm{df}=4)=3, \mathrm{p}>.001$. The fit measures, CFI and RMSEA remained similar given the constraints. In simple terms, the increase in the Chi-square values from the unrestricted model to the constrained model did not produce a poorer fit model. The path 
coefficients did not vary significantly across gender. It is justifiable then to conclude that gender did not interact with the exogenous variables to influence student's intention to pursue science; hence, in this study, gender was not a moderating variable.

Similar patterns of results, which were of statistically insignificant $\Delta \chi 2$ were observed in the other multiple group analyses. The ethnic invariance test yielded no-difference statistics between Malay and non-Malay students. The interactions between ethnic groups and the four exogenous variables did not produce inconsistent results in student intention. Likewise, differences in school location (urban versus rural) did not affect the structural paths of the model. Thus both ethnicity and location did not moderate the causal relationships. In summary, the four-predictor student-intention-to-enrol-in-science model was applicable regardless of gender, ethnicity, and location.

\section{Conclusions}

To explain what triggers 15 -year old students' intention to enroll in science subjects, the study integrated two major theories - the theories of Planned Behaviour and sense of efficacy. The results supported the expectation that students' attitude, perceived difficulty of science, subjective norm, and science self-efficacy collectively explain the reasons why students chose or shied away from the sciences. The effects of the predictors were substantial, accounting for $54 \%$ of the variance in intention. Related previous studies on behavioural intention yielded somewhat similar effects $[16,8]$.

Of the four constructs, attitude was the most influential predictor of students' choice to pursue science, functioning at a higher probability level than perceived difficulty, subjective norms, and science self-efficacy. The finding is consistent with the prevailing presumption that attitude exerts a strong influence on one's judgments, decisions, and behavioural intention. Equally noteworthy is the statistically significant and practically important effects of science-efficacy on intention. Thus far, the effects of self-efficacy on students' academic choices, in the presence of the three exogenous constructs of theory of planned behaviour, are yet to be documented. The results indicated that students' intention to pursue science does not depend only on attitudinal factors, but also on the confidence they have in their ability to succeed in the subjects. Perceived difficulty was also found to be a statistically significant predictor, and the effect size was of practical value. Nevertheless, replicating earlier finding [12], the current study found that the effect of subjective norm was statistically insignificant, with negligible effect.

The present study offers evidence that the four-predictor intention model explains student's intention to take up science subjects. Invariably the structural relationships hold across gender, ethnic group, and urban/rural location. The inclusion of gender into the equation keeps the fact that attitude, perceived difficulty of science, social pressure, and science-efficacy collectively determined student's intention to pursue science. That gender did not moderate the model was likely due to the absence of gaps and stereotyping in the educational treatment, opportunities, and science learning experiences of both boys and girls at school and at home. A similar line of argument is reasonable to justify the lack of moderating effects of ethnic groups and school location, thereby producing comparable patterns of causal structure.

Limited within the chosen framework, the results offer several paths for further research on student enrolment in science. First, it is necessary to dig deeper into other manipulative predictors of student intention to pursue science. Specifically, future studies may consider adding students' prior knowledge, be it objective or subjective scientific knowledge, into the equation. Second, cross-validations of the causal model of behavioural intention to pursue science are needed to determine its efficacy in different contexts and cultures. It is also important that robust longitudinal and panel data research be conducted to identify the stability of the model across time. In addition, there should be more experimental intervention with randomized controlled trials in future studies. Well-planned experimental intervention studies will not only inform us about what drives students to enroll in science, but will also enable research to profoundly advise and convince policy makers about evidence-based strategies and programs to promote greater student participation in the field.

Despite its limitations, the study offers practical contributions to educational practice. The results suggest that the planning, implementation and evaluation of efforts to enhance science participation among students should consider how to develop students' science-efficacy and positive attitudes towards the subjects. Clearly, there is room for parents and teachers, in particular career counselors, to design meaningful strategies and programs. In fact, the present study found evidence that teachers and career counselors have yet to put their stamp of influence on students' choice of science studies. Enhancing attitudes and self-efficacy would be likely to make a difference in intention, thereby increasing students' participation and enrolment in science.

\section{REFERENCES}

[1] P. Potvin and A. Hasni, "Analysis of the decline in interest towards school science and technology from grades 5," Journal of Science Education and Technology, vol. 23 no. 6, pp. 784-802, 2014.

[2] T. M. Akram, A. Ijaz, and H. Ikran, "Exploring the factors responsible for declining students'interest in chemistry," International Journal of Information and Education Technology," vol. 7, no. 2, pp. 88-94, 2017. 
[3] B. J. Ogunkola and D. Samuel, "Science teachers' and students'perceived difficult topics in the integrated science curriculum of lower secondary schools in barbados," World Journal of Education, vol.1, no. 2, 2011

[4] S. A. Jegede, "Students' anxiety towards the learning of chemistry in some Nigerian secondary schools," Educational Research and Reviews, vol. 2, no. 7, pp. 193-197, 2007.

[5] A. M. Masnick, S. S. Valenti, B. D. Cox, and C. J. Osman, "A multidimensional scaling analysis of students' attitudes about science careers," International Journal of Science Education, vol. 32, no. 5, pp. 653-667, 2010.

[6] Z. Hazari, G. Potvin, J. D. Cribbs, A. Godwin, T. D. Scott, and L. Klotz, "Interest in STEM is contagious for students in biology, chemistry, and physics classes," Sci. Adv., (2017)/

[7] P. Kraft, J. Rise, S. Sutton, E. Røysamb, E. 2005. "Perceived difficulty in the theory of planned behaviour: Perceived behavioural control or affective attitude?" British Journal of Social Psychology, vol. 44, pp. 479-496, 2005.

[8] A. Krapp and M. Prenzel, M. "Research on interest in science: Theories, methods, and findings," International Journal of Science Education, vol. 3, no 1, pp. 27-50, 2011

[9] E.L. Deci, 1992. The relation of interest to the motivation of behavior: a self determination theory perspective. In K.A. Renninger, S. Hidi \& A. Krapp (Eds.), The role of interest in learning and development (pp. 43-71). Erlbaum: Hillsdale, NJ, 1992.

[10] S. Hidi, "Interest, Reading, and learning: Theoretical and Practical considerations," Educational Psychology Review, vol. 13, no. 3, pp. 191-209, 2001

[11] B.J. Cridge and A.G. Cridge, "Evaluating how universities engage school students with science: A model based on the analysis of the literature," Australian University Review, vol. 57, no. 1, pp. 34-44, 2015.

[12] F. A. Phang, M.S. Abu, M. B. Ali, and S. Salleh, Determinants of decreasing students' participation in science stream. Sains Humanika, vol. 2 no. 4, pp. 63-71, 2014.

[13] Ajzen, I. and Fishbein, M. 1980. Understanding attitudes and predicting social behavior. Englewood Cliffs, NJ: Prentice-Hall.

[14] Committee on Communication for Behavior Change in the 21st Century. 2002. Speaking of Health: Assessing Health Communication Strategies for Diverse Populations. Washington, DC: National Academies Press, p. 31.

[15] Ajzen, I. and Madden, T. J. 1986. Prediction of goal-directed behavior: Attitudes, intentions and perceived behavioral control. Journal of Experimental Social Psychology, 22, $453-474$.

[16] Bandura, A. 1977. Self-efficacy: Toward a unifying theory of behavioral change. Psychological Review, 84, 191-215. https://doi.org/10.1016/0146-6402 (78)90002-4

[17] Joreskog, K. G. 1993. Testing structural equation models. In K. A. Bollen \& J. S. Long (Eds.), Testing structural equation models (pp. 294-316). Newbury Park, CA: Sage. 